\title{
AC 2010-96: NANOPARTICLE SYNTHESIS TO APPLICATION: A NANOBIOTECHNOLOGY LAB COURSE FOR BIOMEDICAL ENGINEERING
}

Sarah Pierce, Cumberland University

Amanda Lowery, Vanderbilt University

Charleson Bell, Vanderbilt University

Todd Giorgio, Vanderbilt University 


\section{Nanoparticle Synthesis to Application: a Nanobiotechnology Lab Course for Biomedical Engineering}

\section{Introduction}

The investigation of living systems using nanoscale technologies has evolved into a new field of research, bionanotechnology. Bionanotechnology is the development of novel technology at the nanoscale level that is used to interface with biological systems. This highly interdisciplinary area integrates knowledge from traditional fields of study such as engineering, chemistry, physics, biology, material science and medicine. The advent of bionanotechnology is changing the way traditional nanotechnology courses are taught. These courses are shifting from pure nanoparticle (NP) synthesis and characterization to include the interaction of NPs in biological systems.

Laboratories provide students the opportunity to apply new knowledge in a simulated situation and enable the student to achieve learning objectives not easily obtained in the classroom. Fiesel and Rosa identify several general learning objectives for laboratory courses including instrumentation, modeling, experimentation, data analysis, communication, and teamwork. ${ }^{1}$ To achieve these learning objectives, practical hands-on application of concepts from a course and technical skills must be practiced. Additionally, Edward surveyed engineering students and found the students believe laboratory courses are essential to gaining a full understanding of course material. ${ }^{2}$ A bionanotechnology course, when housed within an engineering discipline, benefits from a lab by the active application of ideas and concepts presented in the lecture. Laboratory courses also appeal to the kinesthetic, self-proclaimed "practical" personality of many engineering students. ${ }^{2}$

This bionanotechnology laboratory course has been developed to accompany a three hour bionanotechnology lecture course that uses the textbook Nanotechnology in Biology and Medicine: Methods, Devices, and Applications by Tuan Vo-Dinh. ${ }^{3}$ The biomedical engineering (BME) course is designed for $4^{\text {th }}$ year undergraduates as a one hour BME elective (3 contact hours). The objective of the laboratory is to engage students in nanoparticle development from synthesis to final application, similar to a research laboratory setting. The laboratory exercises are presented as two modules, the first being the synthesis of gold and silver NPs, and the second being the functionalization of quantum dot (QD) NPs with biological molecules such as folic acid. During each module, interaction of these NPs with living systems is evaluated and lab activities are correlated to the lectures. The learning outcomes of these labs are listed and coordinated with Fiesel's learning outcomes in Table 1.

The first module addresses NP toxicity, specifically the toxicity of gold and silver NP when interacting with cells. The toxicity of NPs has been a highly debated area of research. ${ }^{4-6}$ The biological effects of nanoparticles depend on composition, surface charge, size, concentration, cell type, and other factors. In this module, students synthesized gold and silver NPs prepared by sodium borohydride precipitation and characterized the particles by optical spectroscopy and dynamic light scattering (DLS). ${ }^{7,8}$ The students conducted in vitro NP toxicology studies on a human cell line and quantified the viability of the cells by fluorescence flow cytometry. The prelaboratory preparation included readings pertaining to NP toxicity. ${ }^{6}$ During this module, in 
lecture, the students were studying self-assemble of nanoparticles and the application of gold nanoparticles for diagnostics and therapeutics.

The second module of the course was devoted to functionalization of NPs with a biologically active molecule. The development of targeting methods to improve the spatial and temporal delivery of nanoparticles in vivo has enabled specific cellular delivery ${ }^{9-12}$ and subcellular localization of NPs. ${ }^{13-16}$ Students conjugated folic acid (FA) molecules with QD NPs ${ }^{12,17,18}$ and characterized the effects of conjugation on the optically active NPs using gel electrophoresis and DLS. The NPs were used to demonstrate active targeting in vitro on human breast cancer cells. The pre-laboratory preparation included a review that covered concepts involved in specific and non-specific binding as well as the role of cell surface receptors in cancer targeting. ${ }^{19,20}$ Lecture topics relating to this module included quantum dots, optical properties of nanoparticles, and nanoparticles as biosensors.

The formative assessment of the laboratory course is based on participation in the lab, observation of laboratory techniques and safety, documentation within the laboratory notebook including analysis of results and completion of discussion questions. The final summative assessment is a formal laboratory report. At the completion of the course, students were able to synthesize gold and silver NPs, characterize the physical properties of the NPs, functionalize NP surfaces with biomolecules, and conduct studies to determine the NP behavior in living systems, including evaluating toxicity and ligand-receptor specific interactions. These activities reinforce structure-function relationships through the chemical makeup of the bare NP and modified functionalized surfaces presented to the living system.

Table 1: Learning outcomes for the bionanotechnology laboratory course.

\begin{tabular}{|c|l|}
\hline $\begin{array}{c}\text { General Learning } \\
\text { Objectives }\end{array}$ & \multicolumn{1}{|c|}{ Course Specific Learning Objectives } \\
\hline \multirow{2}{*}{ Instrumentation } & $\begin{array}{l}\text { Describe the function and operation laboratory equipment } \\
\text { including dynamic light scattering (DLS), flow cytometry, pipette, } \\
\text { sterile hood, UV-Vis spectrometer, fluorescence microscope and } \\
\text { gel electrophoresis apparatus }\end{array}$ \\
\hline Modeling & Develop technical skills to maintain a sterile in vitro cell model \\
\hline \multirow{2}{*}{ Experimentation } & Perform laboratory procedures by following a written protocol \\
\cline { 2 - 2 } Data Analysis & $\begin{array}{l}\text { Pollect appropriate data from instruments and models listed above } \\
\text { deviation }\end{array}$ \\
\hline \multirow{2}{*}{ Communication } & $\begin{array}{l}\text { Present the collected data in support of a conclusion in the form of } \\
\text { a written report }\end{array}$ \\
\hline \multirow{2}{*}{ Teamwork } & Organize experimental workflow \\
\cline { 2 - 2 } & Divide workload to collect data at multiple time points \\
\cline { 2 - 2 } & $\begin{array}{l}\text { Compile the appropriate data to perform analysis and draw } \\
\text { conclusions }\end{array}$ \\
\hline
\end{tabular}




\section{Schedule of student activity}

The bionanotechnology laboratory course is designed for advanced BME undergraduates but does not assume any previous lab experience. The laboratory is a suggested co-requisite of the bionanotechnology course. The course consists of two major and extended lab modules, each spanning three weeks. The first module focuses on evaluating the toxicity of two NPs, while the second looks at the modulation of NP behavior, involving active and passive targeting. In advance of the extended lab modules, all students took a Vanderbilt University safety training course to gain access to the needed instrumentation in the Vanderbilt Institute of Nanoscale Science and Engineering (VINSE) shared resources facility. This included training on the Malvern Zetasizer Nano DLS instrument.

Week 1: The first week was dedicated to the introduction of laboratory safety, proper sterile techniques, preparation of media, and the initial culture of cells. There was a brief lecture on the history of NPs, a cell culture demonstration and practice using sterile technique. The students were instructed on the proper use of the laminar flow hood, centrifuge, hemocytometer, pipettes, and inverted microscope. Each student group received a flask of MDA-MB-231 human epithelial breast cancer cells and supplies required to maintain the cells. The students were required to maintain their culture for the duration of the experiment and subculture the cells into well plates as preparation for the subsequent experiments. This required one person to tend the cells on a non-class day. After completion of the lab tasks, the students had two days to turn in their laboratory notebooks with completed discussion questions.

\section{Module 1: Nanotoxicology}

Week 2: Notebooks were returned with Week 1 discussion questions graded. The class began with a short discussion on NPs and potential toxicity. The groups (each containing two to three students) synthesized both gold and silver NPs by sodium borohydride precipitation. The NPs were then characterized by UV-VIS spectroscopy and DLS. Both these instruments were located in the VINSE. After completion of the lab tasks, the students were advised to complete discussion questions before the Week 3 activities.

Week 3: The lab time was divided among multiple days to accommodate required time points. Day 1: Cells were subcultured and plated into 24-well plates. Day 2: Students estimated the percent of confluent cells by microscope examination of the wells. Gold NPs, silver NPs, or no NPs were added to the wells. Students examined the wells for confluency again on Day 4 and 7.

Week 4: After estimating the confluency, the students conducted a fluorescent viability assay on the cells. Cells were analyzed by flow cytometry. After completion of the lab tasks, the students had two days to turn in their laboratory notebooks with completed discussion questions pertaining to Weeks $2-4$.

\section{Module 2: Active Targeting of NPs to Cancer Cells}

Week 5: Students could pick-up their graded lab notebooks before the lab experiment. The background reading was available through the course website one week prior to the lab. In the 
laboratory, students were engaged in a discussion about the role of the folate receptor in breast cancer targeting and the use of QD for molecular imaging. The students functionalized two QD NPs: one with FA for active targeting and one with polyethylene glycol (PEG) to prevent nonspecific binding as a negative control.

Week 6: Students characterized the functionalized QD from the previous week. Each group determined the concentration of the QD by Beer's law. The conjugation was verified by DLS and gel electrophoresis.

Week 7: The lab time was divided among multiple days to accommodate required time points. Day 1: Cells were subcultured and plated into 24-well plates. Day 2: Students estimated the percent confluent by microscope examination of the wells and incubated the functionalized QD on the cells. Following the incubation period, fluorescence microscopy and flow cytometry were used to determine the targeting efficiency of each QD probe. After completion of the lab tasks, the students had two days to turn in their laboratory notebooks with completed discussion questions pertaining to weeks 5-7. Notebooks were returned within one week.

\section{Final Report}

Students could choose to write a final lab report on either the nanotoxicology lab or the active targeting lab. Students had three weeks following the completion of the active targeting lab to turn in the final report.

\section{Materials and Methods}

\section{Cell Maintenance}

All reagents were obtained from Sigma-Aldrich (St. Louis, MO) unless otherwise noted. MDAMB-231 human epithelial breast adenocarcinoma cells were a gift from a collaborating lab (Vanderbilt University). They were maintained in Minimum Essential Medium (MEM) (Invitrogen, Carlsbad, CA) supplemented with $0.1 \mathrm{mM}$ non-essential amino acids, $1 \mathrm{mM}$ sodium pyruvate, $0.01 \mathrm{mg} / \mathrm{ml}$ bovine insulin, 10\% FBS (Invitrogen), and 1\% penicillin-streptomycin. Cells were maintained at $37^{\circ} \mathrm{C}, 5 \% \mathrm{CO}_{2}$, and $95 \%$ humidity. For experiments, cells were plated at $2.5 \times 10^{4}$ cells $/ \mathrm{cm}^{2}$ in 12 -well tissue culture plates one day prior to the experiment. Cell concentration was determined by hemocytometer count and exclusion of trypan blue.

\section{Silver and Gold NP Synthesis}

Silver and gold NPs were synthesized by reduction in $2 \mathrm{mM}$ sodium borohydride as previously reported. ${ }^{7,8}$ For silver NPs, $1.0 \mathrm{mM}$ silver nitrate was added dropwise into $30 \mathrm{ml}$ of sodium borohydride, swirling the tube occasionally, until a deep yellow color appeared. The final volume of silver nitrite used was approximately $2.5 \mathrm{~mL}$. To synthesize gold NPs, $1.0 \mathrm{mM}$ hydrogen tetrachloroaurate (III) trihydrate was added dropwise into $30 \mathrm{ml}$ of sodium borohydride, swirling the tube occasionally, until a pink or purple color appeared. The final volume of silver nitrite used was approximately $2.5 \mathrm{~mL}$. Both NP suspensions were characterized by UV-Vis spectroscopy (Nanodrop ND3300) and DLS. DLS was conducted on a 
Malvern Nano Series Zetasizer with a $633 \mathrm{~nm}$ laser. The duration of each scan was $60 \mathrm{~s}$ and 3 scans were acquired.

\section{NP Application to Cells}

On day 1 , cells were rinsed once with $700 \mu$ of phosphate buffered saline (PBS) and $700 \mu$ of fresh cell culture media was replaced on the cells. In triplicate, $300 \mu \mathrm{L}$ of gold or silver NPs were added to the designated wells. The last six wells served as NP free controls. Reapplication of fresh media and NPs was completed on day 3 and 6. At those times confluency was estimated by microscopic inspection of the wells.

\section{Analysis of Viability by Flow Cytometry}

On day 8, the confluency was estimated and the cells were prepared for flow cytometry. Cells were rinsed with $700 \mu \mathrm{l}$ of HANKS PBS. Then, $300 \mu \mathrm{L}$ of $10 \mu \mathrm{m}$ calcien stain (viability stain) was added to wells incubated with NPs and three of the NP free control wells. PBS $(300 \mu \mathrm{L})$ was added to the remaining three wells. The cells were incubated at room temperature for 45 minutes. After the incubation, cells were rinsed with PBS once and covered in $300 \mu \mathrm{L}$ of trypsin. The cells were incubated for 5-10 minutes to ensure the cells had detached before adding $600 \mu \mathrm{L}$ of trypsin neutralizing solution. Cells were passed through a $100 \mathrm{um}$ filter as the final step in preparation for flow cytometry (BD FACS Caliber).

\section{Conjugation of FA and PEG to Quantum Dots}

All dilutions and reactions were conducted with $10 \mathrm{mM}$ borate buffer. In two small clean amber vials, $200 \mu \mathrm{L}$ of carboxylated QDs $(1 \mu \mathrm{M})$ were mixed with $10 \mu \mathrm{L}$ of NHS $(5.7 \mathrm{mg} / \mathrm{mL})$ and 10 $\mathrm{uL}$ of EDC $(10 \mathrm{mg} / \mathrm{ml})$. The suspension stirred for 30 minutes. Then, $20 \mu \mathrm{L}$ of FA $(5 \mathrm{mg} / \mathrm{mL})$ was added to one vial, while $20 \mu \mathrm{L}$ of PEG3400 containing an amine moiety $(10 \mathrm{mg} / \mathrm{mL})$ was added to the other. Both were stirred for an additional for 1 hour and purified using dialysis, three exchanges of borate buffer $(10 \mathrm{mM}, \mathrm{pH} 7.4)$ over 24 hours. Materials were characterized by UV-Vis and gel electrophoresis. Absorbance measurements were obtained using a Nanodrop ND3300. Borate buffer (10 mM, pH 7.4) was used as the blank. Absorbance measurements were collected at $519 \mathrm{~nm}$. Gel electrophoresis was conducted on an Invitrogen single comb E-gel ${ }^{\circledR}$ system. A $0.8 \%$ agrose pre-cast gel was used. The E-gel $®$ starter pack contains the electrophoresis apparatus and 6 single comb gels for $\$ 100$.

\section{Incubation of QD with Cells}

Cells were rinsed once with $700 \mu \mathrm{l}$ of PBS and $500 \mu \mathrm{l}$ of fresh cell culture media was replaced on the cells. In triplicate, $25 \mu \mathrm{L}$ of QD-FA or QD-PEG were added to the designated wells. The last three wells served as NP free controls. Cells were incubated 1 hour, rinsed once with PBS, and fresh media was added. The cells were immediately imaged with a Nikon Eclipse TE2000-U inverted microscope. 


\section{Analysis of QD uptake by Flow Cytometry}

Cells were rinsed with PBS once and covered in $200 \mu \mathrm{L}$ of trypsin. The cells were incubated for 5-10 minutes to ensure the cells had detached before adding $500 \mu \mathrm{L}$ of trypsin neutralizing solution (TNS). Cells were transferred to centrifuge tubes and centrifuged for 5 minutes at 200 RPM in the microcentrifuge. The supernatant was removed and replaced with $300 \mu \mathrm{L}$ of TNS. Cells were resuspended and passed through a $100 \mu \mathrm{m}$ filter as the final step in preparation for flow cytometry (BD FACS Caliber).

\section{Results and Discussion}

This laboratory exposed students to NP synthesis, functionalization, characterization, and application as well as new laboratory techniques, equipment, and tissue culture procedures. The advanced undergraduates were able to conduct an experiment, analyze the data, and present the results in an informative manner by the end of the course. All of the data shown and discussed below was collected by the students during the course. During the design of this course, the instructors worked to make the information very accessible to the students and encouraged the students to be fully engaged in the lab
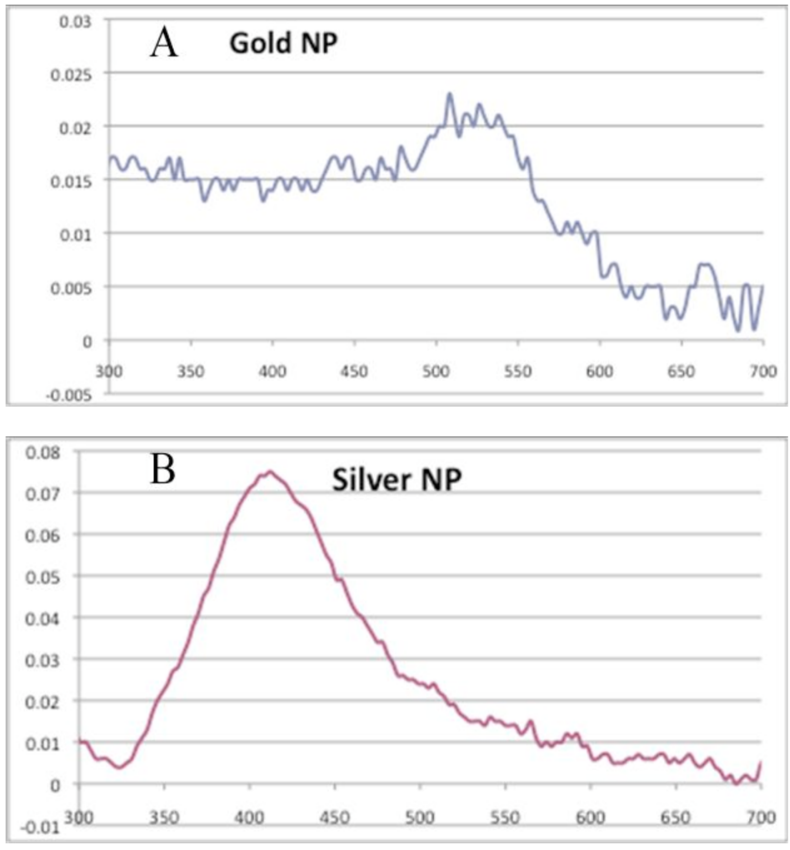

Figure 1: A) Plasmon resonance for gold NP. A maximum was observed at approximately $530 \mathrm{~nm}$. Due to low concentration of nanoparticles, the plasmon resonance peak was discernable but not intense. B) Plasmon resonance for silver NP. A maximum was observed at $410 \mathrm{~nm}$. The $\mathrm{x}$-axis is wavelength $(\mathrm{nm})$. The $y$-axis is absorbance units. exercises. This was the first time this bionanotechnology laboratory course was offered and there are many opportunities to incorporate student independent investigations.

\section{Module 1: Nanotoxicology}

Characterization of gold and silver NPs was conducted using absorbance spectroscopy and DLS. Both the gold and silver NPs have characteristic absorbance peaks measurable by UV-VIS spectroscopy. The absorbance peak for gold NPs is at $530 \mathrm{~nm}$ (Figure 1A). The low signal in the figure is due to the low concentration of the NPs in suspension. For silver NPs, the absorbance peak appears at $410 \mathrm{~nm}$ (Figure 1B). The appearance of these peaks was used to verify the formation of NPs.

DLS determined the average hydrodynamic radius of NPs in suspension based on the angle of light scattered from the particle. The diameters for the gold and silver NPs were $37.5 \pm 3.6 \mathrm{~nm}$ and $7.1 \pm 0.9 \mathrm{~nm}$ respectively. Because the DLS results depend on the deflection of light, the 
concentration of the sample and the refractive index of both the particles and the solvent are important. During synthesis, the size of the particles is dependent on the original concentrations and volumes and the speed of mixing during synthesis. These variables cause some variation in the NP size distribution.

The biological effects of the NPs on MDA-MB-231 cells were monitored for one week. Gold NPs had very little effect on the viability of the cells while the toxic effects of the silver NPs resulted in no viable cells within the one week of exposure (Figure 2). By visual inspection, the MDA-MB-231 cells with the gold NPs continued to proliferate to confluency. Cells exposed to the silver NPs became rounded and detached from the tissue culture surface, indicating a loss of viability. Viability was assessed for the remaining cells using a calcien AM fluorescent viability stain and analysis by flow cytometry. Calcien AM converts to a green fluorescent

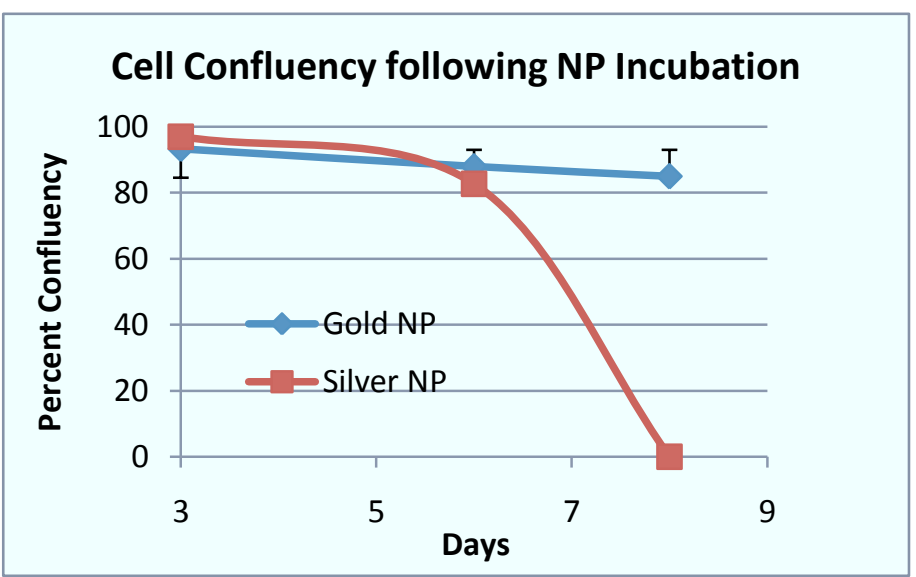

Figure 2: Cell confluency was estimated by microscopic observation on day 3, 6 and 8 for cells incubated with gold or silver nanoparticles. Control cell without nanoparticles maintained confluency over the 8 day period (data not shown). molecule due to hydrolysis by intracellular esterases in live cells. In dead cells, a reduction in the active enzyme prevents the hydrolysis and therefore, there is no fluorescence. Cells incubated with the gold NPs were $85 \pm 2 \%$ viable, according to flow cytometry. This assay could not be performed on the cells incubated with silver NPs because of the low number of cells remaining in the tissue culture dish.

\section{Student Responses to Notebook Questions}

At the conclusion of the module, the students interpreted results from the experiment in their lab notebooks. As a discussion of the results, one student responded:

"We did not do the flow cytometry on the silver exposed cells because there were no cells left so it showed us that the silver nanoparticles did kill the cells. The flow cytometry data showed us that the gold nanoparticles were not toxic. Even though we could see cells in our microscope we needed to use the live assay and flow cytometry to prove that the cells exposed to the gold nanoparticles were viable. The calcein AM on the gold NP cells was enzymatically converted to the fluorescent dye so it showed us the gold NP cells were healthy and viable cells."

The student responses demonstrated their depth of understanding and advanced their mastery of the scientific communication learning objectives. 


\section{Module 2: Active Targeting of NPs to Cancer Cells}

FA molecules were conjugated to carboxylated QDs using an EDC reaction wherein the amine functional group on the FA reacts with the carboxyl group on the surface of the QD. The conjugation methodology was the same for the QD-PEG construct. The concentration of the purified construct was determined by UV-VIS spectroscopy. The absorbance of the construct was obtained at $519 \mathrm{~nm}$ and the concentration was calculated by the students using Beer's Law $(A=E b c)$. In this equation, $\mathrm{A}$ is absorbance, $\mathrm{E}$ is molar absorptivity, $\mathrm{b}$ is pathlength and $\mathrm{c}$ is concentration. The molar absorptivity of $585 \mathrm{~nm}$ QDs is 450,000 $\mathrm{L} \mathrm{mol}^{-1} \mathrm{~cm}^{-1}$.

The concentration of the QD construct is important because when running a gel electrophoresis all concentrations of the samples need to be approximately the same. Otherwise, saturation of the sample will occur, which makes discerning the individual bands on the gel difficult for the students. The conjugation was confirmed by gel electrophoresis (Figure 3). Unmodified QDs (lane 1) were compared to QD functionalized with FA (lane 2) and PEG (lane 3). As the molecular weight of the construct increases, the retention of the construct increases, confirming that the molecules are functionalized on the surface of the NPs.

Once functionalization was confirmed, the students incubated QD-FA and QD-PEG with MD-MBA-231 breast cancer cells. The cells were imaged using a fluorescence microscope (Figure 4). The cells that were incubated with QD-FA fluoresce brightly. The fluorescence in the cells that were incubated with QD-PEG was greatly reduced as compared with the cells that were incubated with QD-FA NPs. Once the cells were imaged, they were immediately prepared for flow cytometry. According to flow cytometry, $83.3 \pm 4.5 \%$ of the cells incubated with QD-FA were fluorescent, compared to $0.76 \pm 0.2 \%$ of the cells incubated with QD-PEG (Figure 5). Only $0.75 \pm 0.03 \%$ of the control cells (blank) incubated without either QD construct exhibited fluorescence.

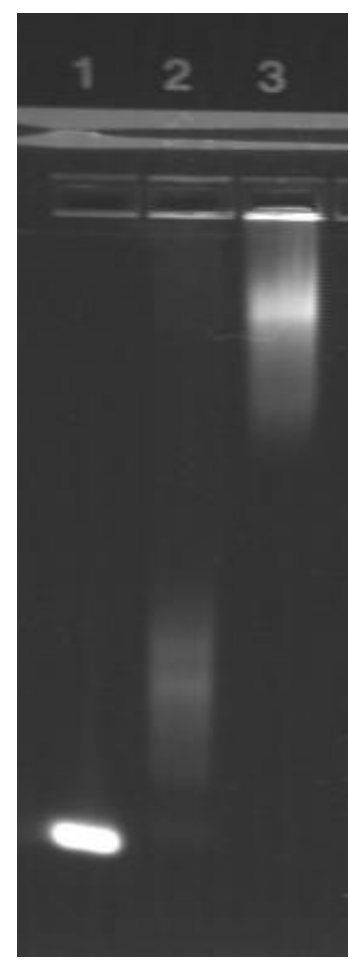

Figure 3: Gel electrophoresis characterization of QDs.

Unfunctionalized QD (lane 1), QD-FA (lane 2), and QD-PEG (lane 3).

\section{Student Responses to Notebook Questions}

In addition to writing an introduction, experimental section, results and discussion and conclusion to each weekly experiment, the students also answered specific questions in their lab notebooks due to the complexity of the labs. For example, the students were asked to interpret the data from the gel electrophoresis and how it confirmed (or rejected) the hypothesis that a ligand is functionalized on the surface of the QD. One student answered as follows: 


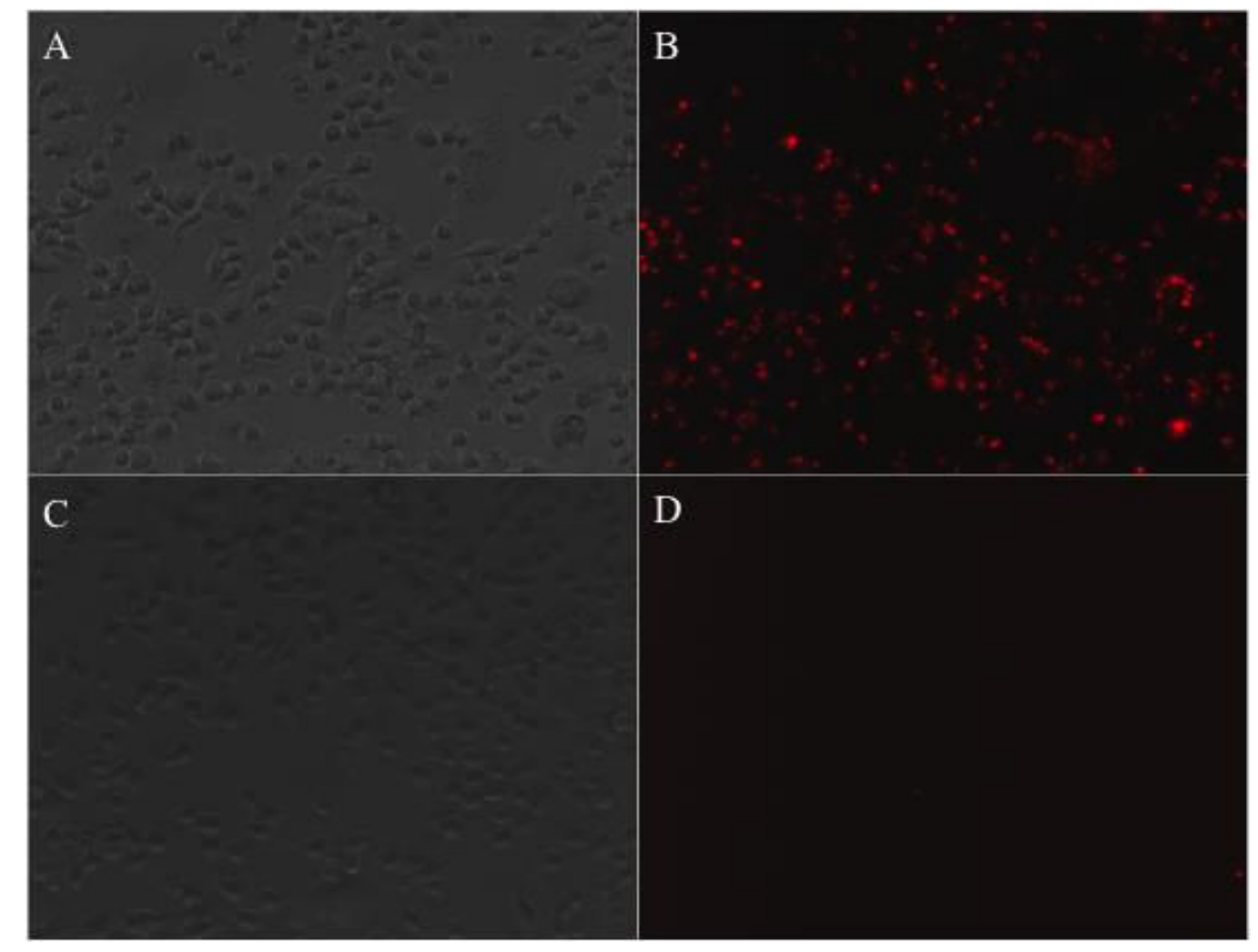

Figure 4: A) Phase contrast image of cells labeled with QD-FA nanoparticles. B) The bright red fluorescent images correspond to QD fluorescence demonstrating the association of QD-FA with the cells.

C) Phase contrast image of cells incubated with QD-PEG nanoparticles

D) The corresponding fluorescence image shows very little red fluorescence indicating the QD-PEG was unable to bind to the cells.

"Two things determine how far something travels on the gel electrophoresis, its charge and its size. The plain QDs and the QD-FA are both negatively charged and the FA makes it a little heavier since its molecular weight is $441.41 \mathrm{~g} / \mathrm{mol}$. As a result the band of FA travels just a little shorter than our QDs. The PEG on the other hand is neutral and very heavy (mw 3400).

Because it is neutral, it is not pulled as far by the positive charge on the opposite side and its size

also makes it travel very slowly so its band doesn't move very far. Our gel is consistent with this so we can conclude our QDs were functionalize with FA and PEG."

Additionally, the students were asked if the QD-PEG or QD-FA samples were fluorescent according to the data gathered from the flow cytometer. They were also asked to explain why the samples would be fluorescent. One student answered,

"The QD-FA sample is fluorescent, but the QD-PEG is not. The QD-PEGs do not have receptors on the breast cancer cells so they did not bind to the cells and were washed off so there are no quantum dots to fluoresce in the sample. The QD-FA on the other hand has folic acid receptors on the cells which they bind to. In the flow cytometer, the QDs emit fluorescence and are detected." 


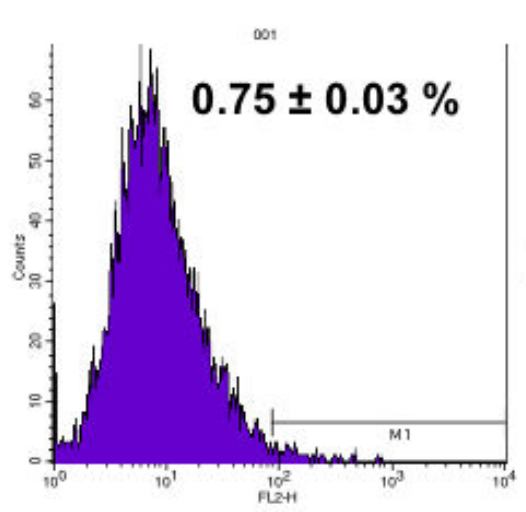

Blank Cells

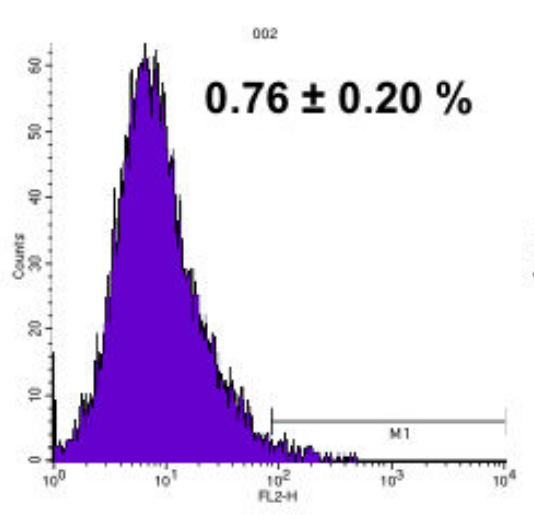

QD-PEG

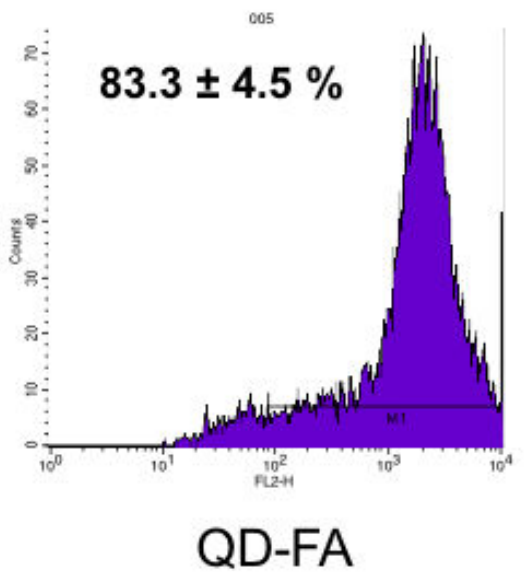

Figure 5: Flow cytometry of blank cells, cells incubated with QD-PEG and cells incubated with QD-FA. The x-axis (FL2-H) is the fluorescence intensity of individual cells. The yaxis is the number of cells exhibiting each fluorescence intensity.

\section{Assessment and Evaluation}

Assessment of the learning objectives was conducted by formative and summative methods. The objectives pertaining to instrumentation, modeling, experimental procedures and teamwork were evaluated during the practical execution in the laboratory period. Data analysis and scientific communication skills were assessed by grading the laboratory notebooks and final reports. The students were required to write a formal lab report on one of the two modules. The students could choose either module, depending on their interest. By writing the lab report, students compiled three weeks of experiments for each module into one cohesive report. The formal lab report included an abstract, an introduction, experimental section, results and discussion, conclusion and references. For some students, assembling the information from three weeks of experiments and communicating the results proved to be a challenge. All the students completed the lab reports and $60 \%$ of the students demonstrated a mastery of critical thinking skills required to compose such a report.

When students were surveyed at the end of the course, their comments about the course were very positive about the quality of the laboratory and the material the students were exposed to. One student commented, "This was by far the best run lab I have ever taken possibly at Vanderbilt and definitely in the engineering department. All the labs were laid out so they were easy to understand, taught good lab technique, and made you think thoroughly about what you were doing. We really need more labs like this." Another student commented, "I loved this lab. When I mentioned what we did in the lab to other in related fields (Drs, researchers, surgeons, etc.) they were extremely impressed by the material covered. I think the things learned in this lab are very pertinent to a wide variety of jobs in biotech, not just in research as the techniques used are necessary to understand many aspects in bioscience." 


\section{Instructor Prep and Involvement}

This was the first time a bionanotechnology laboratory course was offered. The completely new lab exercises required new readings, new protocols, and new discussion questions. The teaching assistant completed each exercise in a trial run before the course began. The trial run determined the clarity of the protocols and the appropriate time points for student data collection. This type of verification is expected for a new course but did add to the teaching assistant responsibilities. During each lab period both the instructor and TA were present and available for student guidance. During the predetermined additional time points either the instructor or the TA was available. Because of the "out of class" time points and lab duties, the instructor had to be flexible to accommodate student schedules. Several experimental design aspects had to be considered to keep the exercises running smoothly. The FA cellular uptake and the NP toxicity are both cell type dependent, making the predetermination of the time point critical. Also, many of the instruments were located in a shared facility and not dedicated for use by this class. Instrument time had to be scheduled in advance. With careful planning the course went smoothly.

\section{Future Directions}

Students mastered many lab techniques and explored NP topics not previously offered in another course at Vanderbilt University. The multi-week extended in-depth study on a single NP type was a deviation from other laboratory courses. This approach allowed the students to develop an invested interest in topics while learning the new techniques.

To allow the students to apply their new knowledge, an independent self-directed experiment could be added to the course. After further independent literature research, students could design other experiments based on toxicity or active targeting. Depending on the availability of supplies, students may change cell lines, targeting agents, or pre-treat the cells to change the biological response. Students can compare their findings to literature reported results and write a report in support of their conclusions.

\section{References}

1. Feisel, L.D. \& Rosa, A.J. The Role of Laboratoies in Undergraduate Engineering Education. Journal of Engineering Education 94, 121-130 (2005).

2. Edward, N.S. The role of laboratory work in endineering education: student and staff perceptions. International Journal of Electrical Engineering Education 39, 11-19 (2002).

3. Vo-Dinh, T. Nanotechnology in Biology and Medicine: Methods, Devices, and Applications, Edn. 1. (CRC Press Taylor \& Francis Group, Boca Raton, FL; 2007).

4. Amin, R.M., Mohamed, M.B., Ramadan, M.A., Verwanger, T. \& Krammer, B. Rapid and sensitive microplate assay for screening the effect of silver and gold nanoparticles on bacteria Nanomedicine 4, 637643 (2009).

5. Bar-Ilan, O., Albrecht, R.M., Fako, V.E. \& Furgeson, D.Y. Toxicity Assessments of Multisized Gold and Silver Nanoparticles in Zebrafish Embryos Small 5, 1897-1910 (2009).

6. Chen, Y.-S., Hung, Y.-C., Liau, I. \& Huang, G.S. Assessment of the in vivo toxicity of gold nanoparticles Nanoscale Research Letters 4, 858-864 (2009). 
7. McFarland, A.D., Haynes, C.L., Mirkin, C.A., Duyne, R.P.V. \& Godwin, H.A. Color My Nanoworld. Journal of Chemical Education 81, 544A-544B (2004).

8. Solomon, S.D. et al. Synthesis and Study of Silver Nanoparticles. Journal of Chemical Education 84, 322325 (2007).

9. Ivanenkov, V.V., Felici, F. \& Menon, A.G. Targeted delivery of multivalent phage display vectors into mammalian cells. Biochim Biophys Acta 1448, 463-472 (1999).

10. Loo, C., Lowery, A., Halas, N., West, J. \& Drezek, R. Immunotargeted nanoshells for integrated cancer imaging and therapy. Nano Lett 5, 709-711 (2005).

11. Lowery, A.R., Gobin, A.M., Day, E.S., Halas, N.J. \& West, J.L. Immunonanoshells for targeted photothermal ablation of tumor cells. Int J Nanomedicine 1, 149-154 (2006).

12. Smith, R., Sewell, S.L. \& Giorgio, T.D. Proximity-activated nanoparticles: in vitro performance of specific structural modification by enzymatic cleavage. Int J Nanomedicine 3, 95-103 (2008).

13. Finka, A. et al. Targeting and magnetic separation of mitochondria using functionalized superparamagnetic nanoparticles. In preparation (2009).

14. Kau, T.R., Way, J.C. \& Silver, P.A. Nuclear transport and cancer: from mechanism to intervention. Nat Rev Cancer 4, 106-117 (2004).

15. Lowery, A.R., Finka, A., Weiner, A.A., Hubbell, J.A. \& Giorgio, T.D. Intracellular Phage Display Reveals Cell Type Specific Nuclear-Targeting Peptides. BMC Cancer (in review).

16. Yoshikawa, T. et al. Organelle-targeted delivery of biological macromolecules using the protein transduction domain: potential applications for Peptide aptamer delivery into the nucleus. J Mol Biol 380, 777-782 (2008).

17. Bharali, D.J., Lucey, D.W., Jayakumar, H., Pudavar, H.E. \& Prasad, P.N. Folate-Receptor-Mediated Delivery of InP Quantum Dots for Bioimaging Using Confocal and Two-Photon Microscopy Journal of American Chemical Society 127, 11364-11371 (2007).

18. Sewell, S.L. \& Giorgio, T.D. Synthesis and enzymatic cleavage of dual-ligand quantum dots. Materials Science and Engineering C 29, 1428-1432 (2009).

19. Gao, X., Cui, Y., Levenson, R.M., Chung, L.W.K. \& Nie, S. In vivo cancer targeting and imaging with semiconductor quantum dots. Nature Biotechnology 22, 969-976 (2004).

20. Koo, O.M., Rubinstein, I. \& Onyuksel, H. Role of nanotechnology in targeted drug delivery and imaging: a concise review. Nanomedicine: Nanotechnology, Biology, and Medicine 1, 193-212 (2005). 